\title{
SISTEM INFORMASI PROGRAM PELAPORAN ISPA DI KOTA SURABAYA
}

\section{INFORMATION SYSTEM OF ACUTE RESPIRATORY INFECTIONS (ARI) REPORTING PROGRAM IN SURABAYA}

\author{
Nur Fauzia Laily Mubarokah ${ }^{1}$, Hari Basuki Notobroto ${ }^{2}$, Primayanti ${ }^{3}$ \\ ${ }_{1,2}$ Departemen Biostatistika dan Kependudukan \\ Fakultas Kesehatan Masyarakat Universitas Airlangga \\ Jl. Mulyorejo Kampus C Unair Surabaya, Jawa Timur 60115, Indonesia \\ ${ }^{3}$ Dinas Kesehatan Kota Surabaya \\ J1. Jemursari No 197 Surabaya, Jawa Timur 60239, Indonesia \\ Alamat Korespondensi: Nur Fauzia Laily Mubarokah \\ E-mail: nur.fauzia.laily-2015@fkm.unair.ac.id
}

\begin{abstract}
Acute Respiratory Infections (ARI) is a disease that occurs in many developing countries and also on the list of 10 most diseases in hospitals. This study aims to analyze the information system of ARI Reporting Program in Surabaya. Reporting on ARI cases is a surveillance of the disease. If many cases reported, it is better than only a few cases reported. This research is a descriptive study with a qualitative approach. Based on the results of the interview with the informant, it was stated that the ARI reporting program had helped in recording ARI cases that occurred in Surabaya. File formats that are still manual and not integrated with the internet (online) make sending reports longer. Even if you implement an integrated online, data entry only needs to be done once so that the same data will be stored electronically and can be sent and processed. In addition, in the excel file ARI reporting program, there are several output menus that can be used as a result of the description of ARI cases. However, the output was underutilized so that less case monitoring was implemented to reduce the number of ARI / Pneumonia cases that occurred in Surabaya. The conclusion is the ARI reporting program is very helpful in the process of data collection of ARI cases, but it would be better if they use the type of online computerization management and better utilize the graphical output of the ARI reporting program.
\end{abstract}

Keywords: acute respiratory infection, reporting program, online

\begin{abstract}
ABSTRAK
Infeksi Saluran Pernapasan Akut (ISPA) merupakan penyakit yang banyak terjadi di negara berkembang dan berada pada daftar 10 penyakit terbanyak di rumah sakit. Penelitian ini bertujuan untuk mengetahui dan mempelajari sistem informasi Program Pelaporan ISPA di Kota Surabaya. Pelaporan kasus ISPA merupakan surveilans dari penyakit tersebut. Apabila banyaknya kasus yang dilaporkan, maka dinilai lebih baik daripada hanya ada sedikit kasus yang dilaporkan. Penelitian ini merupakan penelitian deskriptif dengan pendekatan kualitatif menggunakan data primer hasil wawancara. Berdasarkan hasil wawancara dengan narasumber disebutkan bahwa program pelaporan ISPA yang sudah digunakan telah membantu dalam mencatat kasus ISPA yang terjadi di Kota Surabaya. Form tersebut juga dapat digunakan untuk mencatat kasus pneumonia balita, PWS, cakupan per lokasi, dsb. Padahal apabila menerapkan Sistem Informasi Kesehatan secara online, petugas hanya perlu memasukkan data satu kali maka data tersebut akan tersimpan secara elektronik dan dapat dikirim serta diolah menjadi informasi. Selain itu, pada file excel program pelaporan ISPA terdapat beberapa menu output yang dapat dimanfaatkan sebagai hasil gambaran dari banyaknya kasus pneumonia dan ISPA yang terjadi di wilayah kerja puskesmas tertentu. Namun, output tersebut kurang dimanfaatkan sehingga monitoring kasus kurang diterapkan untuk mengurangi jumlah kasus yang terjadi di Kota Surabaya. Kesimpulannya adalah program pelaporan ISPA sangat membantu dalam proses pendataan dan
\end{abstract}


penggambaran kasus ISPA, namun akan lebih baik apabila menggunakan tipe pengelolaan komputerisasi online serta lebih memanfaatkan output grafik dari program pelaporan ISPA tersebut.

Kata kunci: infeksi saluran pernafasan akut, program pelaporan, online

\section{PENDAHULUAN}

Perkembangan teknologi menjadi salah satu dampak dari globalisasi. Teknologi berkembang dengan sangat pesat ditandai dengan semakin banyaknya peralatan canggih yang dapat menunjang kehidupan manusia. Salah satu teknologi yang berkembang sangat cepat yakni teknologi informasi. Teknologi informasi memiliki peran dalam hal pengolahan data. Peran teknologi informasi lebih menekankan pada pengaturan sistem informasi serta dapat memenuhi kebutuhan organisasi secara tepat waktu, relevan, dan akurat. Teknologi informasi sekarang ini sangat dibutuhkan sehingga penggunaan komputer yang tepat adalah mutlak (Ismanto, 2010).

Dinas Kesehatan Kota Surabaya merupakan satuan kerja pemerintah Kota Surabaya yang sudah menggunakan perangkat komputer sebagai alat penunjang dalam kegiatan pengolahan data. Hal tersebut diharapkan dapat membantu dalam penginputan data sampai pengolahan data menjadi informasi yang berguna untuk penyusunan capaian kinerja pada tahun selanjutnya. Adanya sistem informasi memudahkan pengumpulan laporan bulanan dari puskesmas ke pihak Dinas Kesehatan Kota Surabaya. Banyaknya jenis form laporan yang harus diisi dan dikirim oleh pihak puskesmas diharapkan dapat terbantu dengan adanya sistem informasi yang telah diterapkan. Salah satunya yakni program pelaporan kasus ISPA. Form ini dibuat oleh Kementerian Kesehatan Republik Indonesia dengan format sesuai dengan jumlah kelurahan yang ada di wilayah kerja puskesmas. Form tersebut merupakan softfile dengan ekstensi file excel yang memuat berbagai data dan informasi terkait ISPA. Termasuk di dalamnya adalah pelaporan kasus pneumonia balita.

Infeksi Saluran Pernafasan Akut (ISPA) merupakan penyakit infeksi akut yang terjadi pada bagian saluran napas mulai dari hidung (saluran atas) hingga alveoli (saluran bawah) termasuk jaringan adneksanya seperti sinus, rongga telinga tengah dan pleura (Irianto, 2014). ISPA merupakan penyakit yang banyak terjadi di negara berkembang serta salah satu penyebab kunjungan pasien ke puskesmas $(40 \%-60 \%)$ dan rumah sakit (15\%-30\%). Semua kasus ISPA yang terjadi di masyarakat, $7-13 \%$ merupakan kasus berat dan memerlukan perawatan rumah sakit (Kemenkes RI, 2012).

Kasus ISPA di Indonesia menempati urutan pertama penyebab kematian bayi yaitu sebesar $24,46 \%$ (2013), 29,47\% (2014) dan 63,45\% (2015). Selain itu, penyakit ISPA sering masuk dalam daftar 10 penyakit terbanyak pada rumah sakit (Kemenkes RI, 2016b). Penduduk kondisi ekonomi menengah ke bawah lebih sering terserang penyakit ini (Kemenkes RI, 2013).

Program Pemberantasan Penyakit ISPA dibedakan menjadi dua macam berdasarkan jenisnya, yaitu ISPA non-Pneumonia dan ISPA pneumonia. Kejadian batuk pilek pada balita merupakan ISPA non-pneumonia. Pada umumnya, balita akan menderita batuk pilek sebanyak 3-6 kali dalam setahun. Kasus ISPA Pneumonia pada tahun 2015 ditemukan sebanyak 4.018 kasus (41,44\% dari target nasional), namun pada tahun 2016 mengalami penurunan penemuan kasus menjadi sebanyak 2.915 kasus (Dinkes Kota Surabaya, 2015).

Salah satu masalah kesehatan yang masih terjadi di Indonesia, tidak terkecuali di Surabaya adalah kejadian pneumonia. Kasus pneumonia di Kota Surabaya pada tahun 2012 sampai 2014 mengalami penurunan. Hal tersebut membuktikan bahwa Surabaya mampu menekan angka kejadian pneumonia. Namun, angka kejadian pneumonia di Surabaya masih dinilai cukup tinggi karena Surabaya terdiri dari 31 kecamatan yang pada masing-masing wilayah kecamatannya masih terdapat kasus pneumonia (Aulia, Chamid dan Andari, 2017). 
Pelaporan kasus ISPA merupakan surveilans dari penyakit tersebut. Apabila banyaknya kasus yang dilaporkan, maka dinilai lebih baik daripada hanya ada sedikit kasus yang dilaporkan. Hal tersebut karena kasus ISPA yang dianggap sebagai fenomena gunung es. Pemerintah telah berupaya untuk mencari dan menemukan kasus ISPA sebanyak mungkin agar nantinya tidak menjadi masalah bagi warga Indonesia. Karena pelaporan ISPA, khususnya penumonia yang harus dilakukan dengan cepat, maka perlu adanya sistem informasi pelaporan yang dapat dilakukan untuk mempermudah dan mempercepat proses pelaporan serta pendataan kasus ISPA dan pneumonia balita.

Kasus pneumonia balita dari tiap puskesmas telah disajikan datanya pada Laporan Profil Kesehatan Kota Surabaya. Namun, tidak semua puskesmas mencapai perkiraan tersebut. Jumlah kasus yang ditemukan dan ditangani, sebagian ada yang masih di bawah jumlah perkiraan kasus. Adanya evaluasi pemanfaatan sistem informasi program pelaporan ISPA di Kota Surabaya diharapkan dapat mengurangi jumlah kasus ISPA yang ada di Kota Surabaya.

Penelitian ini bertujuan untuk menganalisis pemanfaatan dan kemudahan penggunaaan sistem informasi Program Pelaporan ISPA dalam menggambarkan kondisi penyakit ISPA dan pneumonia balita di Kota Surabaya.

\section{METODE PENELITIAN}

Penelitian yang dilakukan merupakan penelitian deskriptif dengan pendekatan kualitatif. Penelitian dilakukan dengan melakukan observasi, membuat catatan, dan melakukan wawancara terkait dengan objek yang akan diteliti. Alat bantu yang digunakan dalam penelitian ini adalah alat tulis dan kamera. Teknik pengumpulan data di lapangan yaitu pengamatan (observasi), wawancara, dan analisis dokumen. Wawancara dilakukan pada informan di bagian SIK Dinas Kesehatan Kota Surabaya yang paham mengenai file excel Program Pelaporan ISPA. Dokumen yang dianalisis berkaitan dengan laporan tahunan, profil kesehatan, serta panduan Sistem Informasi Kesehatan. Penelitian ini dilakukan pada bulan Januari di bagian Sistem
Informasi Kesehatan Dinas Kesehatan Kota Surabaya.

\section{HASIL PENELITIAN}

Program Pelaporan ISPA merupakan format file excel yang dibuat oleh Kementerian Kesehatan Republik Indonesia untuk mengumpulkan dan merekap data terkait ISPA dan pneumonia. File tersebut merupakan file offline yang diisi dengan cara manual berdasarkan data yang ada di puskesmas. File tersebut memuat beberapa menu yang dapat dimanfaatkan untuk proses pengolahan dan analisis data terkait ISPA dan pneumonia.

Informan mengatakan, "File excel tersebut dibuat langsung oleh Kementerian Kesehatan RI, sedangkan pihak Dinas Kesehatan Kota Surabaya juga membuat format sendiri untuk memudahkan dalam hal perekapan data setelah menerima laporan dari tiap puskesmas."

Kemenkes RI membuat 5 file dengan format yang sama, yang membedakan hanya jumlah kelurahan yang ada di puskesmas. File tersebut antara lain file 1P, 2P, 3P, 4P, dan 5P. File dari Kemenkes RI yang dikirim ke Dinas Kesehatan Kabupaten/Kota akan didistribusikan kepada semua puskesmas yang berada di daerah tersebut. Puskesmas akan memilih file yang sesuai dengan jumlah kelurahan di wilayah kerja puskesmas yang bersangkutan. Selanjutnya, file tersebut akan diisi sesuai dengan keadaan yang ada di wilayah puskesmas.

Gambar 1 merupakan tampilan awal dari file program pelaporan ISPA. File memuat menu jenis pelaporan, serta puskesmas. Pilihan menu puskemas akan memunculkan pilihan menu bulan dalam satu tahun. Menu tersebut yang digunakan untuk penginputan dan pengolahan data pelaporan kasus ISPA.

Gambar 2 merupakan menu program pelaporan ISPA. Terdapat menu informasi utama, laporan bulanan yang ada di Program Pelaporan ISPA. Selain kedua menu tersebut, masih banyak menu lain yang tersedia di form Program Pelaporan ISPA. Menu lain tersebut lebih mengarah pada output dari data yang dimasukkan pada form. Menu-menu tersebut antara lain; Cakupan/Lokasi, Cakupan/Bulan, 


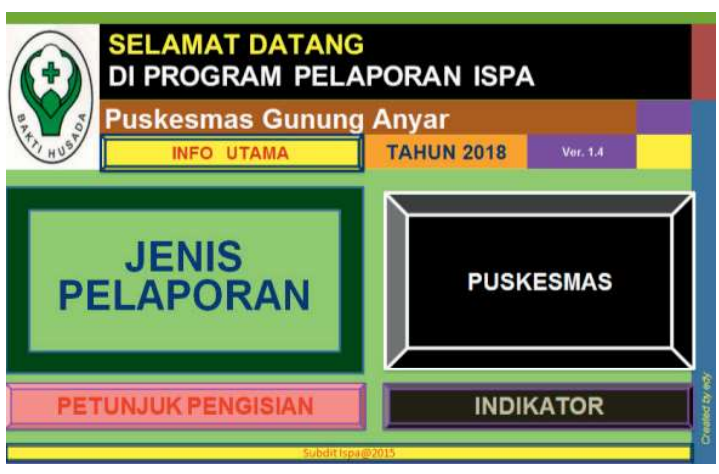

Gambar 1. Tampilan Menu Depan Software Program Pelaporan ISPA

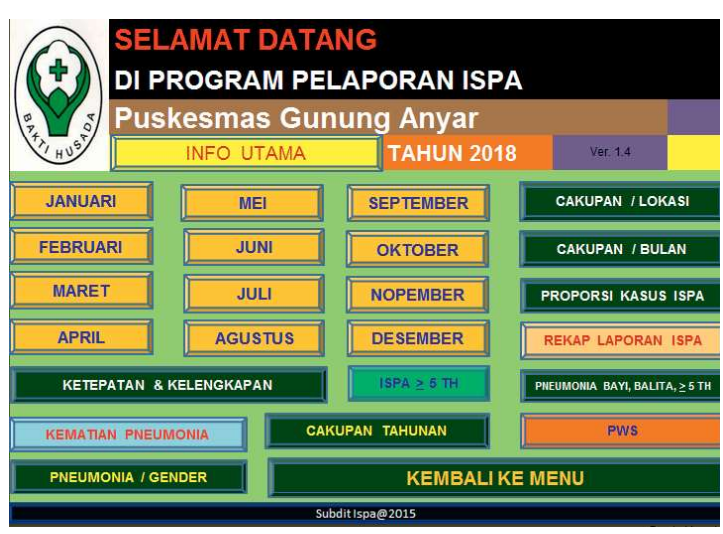

Gambar 2. Tampilan Menu Program Pelaporan ISPA

Proporsi Kasus ISPA, Rekap Laporan ISPA, Pneumonia Bayi, Balita, $\geq 5$ th, PWS, Kematian Pneumonia, Pneumonia/Gender, Cakupan Tahunan, ISPA $\geq 5$ th. Semua menu tersebut menampilkan grafik dari hasil data yang telah diinput pada tiap bulannya.

File kasus tiap bulan yang dikirim dari puskesmas akan direkap oleh Dinas Kesehatan Kota Surabaya berdasarkan kecamatan dan wilayah puskesmas. Data tersebut merupakan hasil dari surveilans yang dilakukan pada wilayah kerja puskesmas dan akan diolah menjadi laporan kasus pneumonia balita yang ditemukan dan ditangani pada laporan Profil Kesehatan Kota Surabaya tiap tahunnya.

"Proses dan alur pelaporan dari semua kasus itu sama, yang membedakan hanya pada jenis dan bentuk formnya", informan menjelaskan mengenai alur pelaporan.
Form Pelaporan ISPA memuat tentang kasus pneumonia yang terjadi di Kota Surabaya. Data tersebut yang nantinya akan dimasukkan pada laporan kasus pneumonia balita di Profil Kesehatan Kota Surabaya terkait dengan penemuan kasus pneumonia balita di Kota Surabaya. Laporan pneumonia merupakan laporan surveilans penyakit. Surveilans dilakukan dengan memantau kejadian secara rutin, mengamati faktor apa saja yang mempengaruhi kejadian penyakit, serta mendeteksi adanya outbreak pada populasi. Hasil surveilans tersebut dapat dijadikan sumber informasi kepada pembuat kebijakan untuk membuat upaya pencegahan dan pengendalian penyakit (Last, 2001).

Keberhasilan program pengendalian pneumonia balita harus ditunjang dengan adanya data epidemiologi penyakit pneumonia yang didapatkan melalui kegiatan surveilans epidemiologi pneumonia. Surveilans pneumonia bermanfaat untuk menghasilkan data yang valid sebagai sumber informasi bagi pembuat kebijakan dalam menentukan tindakan yang tepat untuk penanggulangan dan pengendalian pneumonia balita. Selain itu, hasil surveilans dapat berperan sebagai alat bantu dalam meningkatkan manajemen kasus dan monitoring program P2 ISPA (Depkes RI, 2003).

Keberhasilan surveilans dapat dilihat dari banyaknya kasus ISPA terutama pneumonia balita yang ditemukan dan ditangani pada daerah tersebut. Semakin tinggi persentase jumlah penderita yang ditemukan dan ditangani, maka semakin baik daerah tersebut dalam melakukan surveilans penyakit pneumonia. Namun, apabila jumlah yang ditemukan dan ditangani masih sedikit atau bahkan $0 \%$, dapat dicurigai bahwa daerah tersebut kurang menerapkan surveilans atau mungkin memang pada daerah tersebut tidak terdapat kasus pneumonia balita.

Pentingnya surveilans penyakit dapat membantu mengurangi jumlah kasus yang ada pada daerah tersebut. Semakin banyaknya kasus yang ditemukan dan ditangani, diharapkan dapat mengurangi proses penularan penyakit tersebut. Sehingga dapat mengurangi jumlah kasus ISPA atau pneumonia balita yang terjadi pada daerah tersebut. Namun, apabila persentase surveilans sedikit, berarti daerah tersebut memang tidak 
ada kasus pneumonia balita atau daerah tersebut tidak menerapkan dan memanfaatkan surveilans dengan baik. Hal yang harus diwaspadai adalah apabila suatu daerah belum bisa memanfaatkan dan melakukan surveilans penyakit dengan baik. Hal ini akan berdampak pada penularan penyakit dan meningkatkan jumlah kasus yang ada di daerah tersebut.

\section{PEMBAHASAN}

\section{Mekanisme Sistem Informasi Program Pelaporan ISPA}

Setiap puskesmas wajib mengirimkan laporan bulanan pada Dinas Kesehatan Kota Surabaya paling lambat tanggal 5 setiap bulannya. Laporan bulanan tersebut terdiri dari beberapa macam laporan. Salah satunya mengenai laporan ISPA dan pneumonia. Perekapan kasus ISPA/ pneumonia telah ada format file excel yang dibuat oleh Kementerian Kesehatan Republik Indonesia.

Pengelolaan data dari puskesmas menggunakan tipe pengelolaan komputerisasi offline. Semua unit pelayanan di puskesmas wajib melakukan pencatatan data. Setiap pelayanan yang dilakukan harus dicatat pada sistem pengolah data (komputer) dengan format yang telah ditentukan. Laporan tersebut nantinya akan dikirim ke Dinas Kesehatan Kota Surabaya dalam bentuk softcopy di dalam CD atau flashdisk. Laporan yang dikirim merupakan laporan individual dari tiap puskesmas yang wajib dikirim setiap bulannya. Ketentuan khusus terkait penyimpanan data adalah data harus disimpan dalam komputer selama 10 tahun sebelum dihapuskan.

Setelah data diterima oleh Dinas Kesehatan Kota Surabaya, selanjutnya sistem pengelolaan dari dinas kesehatan akan menghasilkan laporan berupa Profil Kesehatan Kota Surabaya. Dalam sistem pengelolaan data yang dilakukan, pihak Dinas Kesehatan Kota Surabaya merekap semua data yang diterima dari setiap unit layanan kesehatan di wilayah Kota Surabaya. Setiap akhir bulan, data tersebut akan diekspor dari database lokal ke dalam bentuk softfile yang disimpan pada CD atau flashdisk. Laporan hasil rekapan harus dikirimkan pada Dinas Kesehatan Provinsi per tanggal 15 pada tiap bulannya. Ketentuan penyimpanan data dalam komputer harus disimpan selama 5 tahun sebelum dihapuskan.

Laporan bulanan, termasuk laporan kasus ISPA/pneumonia dikumpulkan pada bagian Sistem Informasi Kesehatan di Dinas Kesehatan Kota Surabaya. Pihak SIK akan menerima laporan berupa softcopy dan hardcopy dari masing- masing puskesmas. Unit SIK juga akan melakukan verifikasi terkait dengan laporan yang telah dikirim oleh puskesmas. Hasil verifikasi tersebut akan menetapkan apakah laporan yang dikirim dapat diterima atau tidak oleh unit Sistem Informasi Kesehatan. Apabila laporan tidak dapat diterima, maka laporan tersebut dikembalikan kepada pihak puskesmas untuk diperbaiki.

Jika laporan diterima, maka akan dilanjutkan dengan mengisi checklist laporan dan memberikan tanda terima kepada petugas puskesmas. Laporan softcopy maupun hardcopy yang sudah diabsensi selanjutnya akan dilakukan entry data dan rekapitulasi menggunakan system report excel untuk setiap jenis laporan. Langkah selanjutnya yang tidak kalah penting adalah proses validasi. Validasi dilakukan untuk mendapat persetujuan dari pemegang program pada bidang dan petugas unit Sistem Informasi Kesehatan. Jika validasi data laporan dari puskesmas tidak disetujui, maka akan dilakukan koreksi data oleh puskesmas dan dilakukan validasi kembali. Namun, apabila laporan telah disetujui, maka data tersebut dapat dianalisis.

Herlambang, Aknuranda dan Saputra (2018) membuat sebuah model manajemen strategis pada pelayanan kesehatan primer yang disebut dengan model manajemen Andal. Namun, implementasi dari model tersebut masih terdapat kekurangan. Implementasi model manajemen Andal perlu didukung dengan adanya sistem informasi yang lebih cepat dan mudah dalam proses pengumpulan dan pengolahan data menjadi informasi. Informasi yang dihasilkan nantinya akan digunakan untuk meningkatkan pelayanan kesehatan primer.

Dalam sistem informasi, terdapat input, proses, output dari sistem tersebut. Program Pelaporan ISPA yang berbentuk file excel juga memuat tiga unsur tersebut. Berikut merupakan penjelasan dari input, proses, output dari Program 
Pelaporan ISPA yang telah dimanfaatkan di Puskesmas dan Dinas Kesehatan Kota Surabaya.

\section{Input}

Masukan (input) merupakan kegiatan menambahkan atau memasukkan data yang berupa data fisik maupun non fisik. Data fisik (hardfile) meliputi berkas atau laporan, sedangkan data non fisik (softfile) dapat berupa data dalam $C D$, flashdisk, dan sebagainya. Ketepatan dalam penginputan data menjadi poin penting agar data yang dihasilkan valid.

Software Program Pelaporan ISPA memuat beberapa menu yang mendukung software tersebut. Komponen input memiliki dua menu yang digunakan dalam melengkapi sistem tersebut. Menu tersebut antara lain "info utama" dan "laporan bulanan". Menu "info utama" memuat keterangan yang harus diiisi oleh pihak puskesmas secara lengkap. Semua informasi yang ada wajib diisi dengan lengkap, meliputi nama desa/kelurahan, jumlah penduduk, nama pengelola program di puskesmas, serta masih banyak lagi informasi yang harus dilengkapi terkait dengan data puskesmas.

Selain menu "Info Utama", terdapat menu "Laporan Bulanan" yang dibedakan tiap bulan yang harus diisi oleh pihak puskesmas. Laporan ini merupakan proses input yang paling penting karena memuat informasi terkait dengan banyaknya kasus ISPA/Pneumonia yang terjadi pada wilayah kerja puskesmas tertentu. Laporan tersebut wajib diisi tiap bulannya dan disetor ke Dinas Kesehatan Kota Surabaya pada awal bulan berikutnya. Menu tersebut memuat informasi mengenai jumlah penduduk balita, perkiraan pneumonia, jumlah kasus pneumonia, bukan pneumonia, serta jumlah kematian yang disebabkan oleh pneumonia.

\section{Proses}

Tahap selanjutnya yang dilakukan adalah proses pengolahan yang dapat diartikan sebagai kegiatan mengubah masukan menjadi hasil yang memiliki nilai guna. Proses dari sistem informasi pelaporan kasus ISPA telah dilakukan oleh file software yang berekstensi excel. File excel ini yang dapat memproses data menjadi keluaran sesuai dengan format yang ada.

\section{Output}

Output merupakan hasil dari kegiatan input yang telah diproses dan dapat digunakan oleh pengguna. Output dikatakan baik apabila menghasilkan informasi yang berkualitas. Software Program Pelaporan ISPA, memuat banyak menu output yang dapat dimanfaatkan. Menu output tersebut antara lain; Cakupan/ Lokasi, Cakupan/Bulan, Proporsi Kasus ISPA, Rekap Laporan ISPA, Pneumonia Bayi, Balita, $\geq 5$ th, PWS, Kematian Pneumonia, Pneumonia/ Gender, Cakupan Tahunan, ISPA $\geq 5$ th.

Gambar 3 merupakan tampilan menu output yang diambil dari salah satu file Program Pelaporan ISPA di Puskesmas Gunung Anyar Surabaya. Gambar 3 output grafik tersebut dapat dilihat jumlah penderita pneumonia balita yang ditemukan tiap bulan di wilayah kerja puskesmas Gunung Anyar. Dari grafik tersebut dapat disimpulkan apakah ada peningkatan atau penurunan dari penemuan kasus pneumonia balita yang dihitung setiap bulan. Output tersebut dapat dijadikan bahan evaluasi dari program surveilans yang telah dilakukan pada wilayah kerja puskesmas. Selain itu, terdapat output grafik cakupan program ISPA (Cakupan Tahunan) yang menggambarkan cakupan program ISPA tiap tahun pada Puskesmas Gunung Anyar. Grafik tersebut dapat dijadikan bahan evaluasi dari program ISPA yang selama ini telah dijalankan. Adanya output grafik ini diharapkan dapat membantu pihak puskesmas dalam menilai kinerja program yang selama ini telah dijalankan, serta meningkatkan cakupan program ISPA apabila dinilai kurang.

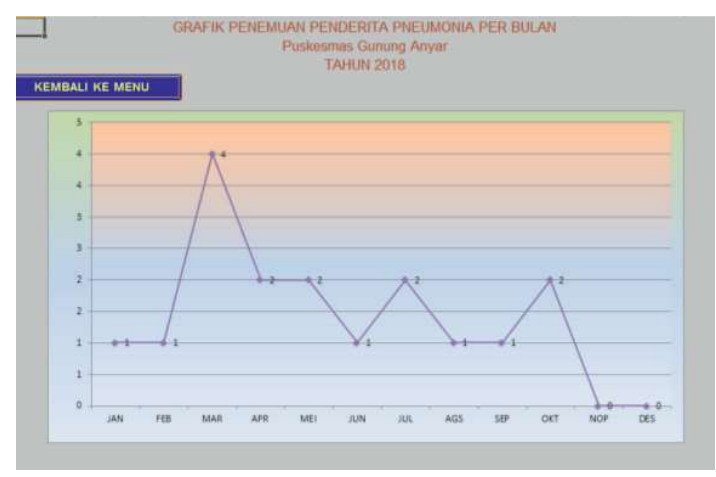

Gambar 3. Output Grafik Penemuan Penderita Pneumonia Balita per Bulan 


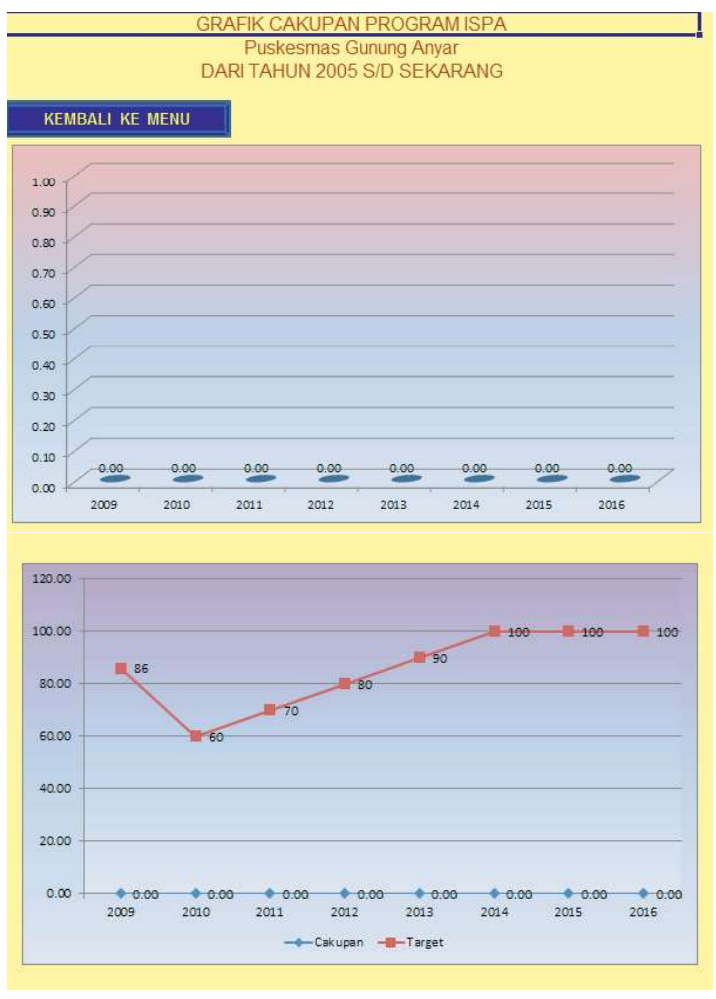

Gambar 4. Output Grafik Cakupan Program ISPA Tiap Tahun

Output yang ada di Program Pelaporan ISPA sudah cukup bisa menggambarkan keadaan suatu wilayah puskesmas terkait dengan masalah ISPA/Pneumonia. Pihak Dinas Kesehatan Kota Surabaya juga menilai bahwa output yang ada dapat membantu dalam proses analisis data. Jenis output yang ditampilkan juga sangat beragam dan memuat semua aspek pada kasus ISPA maupun pneumonia. Mulai dari cakupan tiap lokasi, cakupan menurut gender, cakupan menurut umur sampai dengan jumlah kematian yang disebabkan karena pneumonia.

Semua menu tersebut menampilkan grafik dari hasil data yang telah di input pada tiap bulannya. Namun, seringkali grafik tidak memunculkan informasi yang tepat karena input data bulanan kurang lengkap ataupun data pada info utama belum diisi dengan benar. Hal tersebut dapat mengakibatkan informasi yang dihasilkan kurang valid atau bahkan tidak dapat dipercaya. Pihak puskesmas juga kurang memanfaatkan output yang ada pada Program Pelaporan ISPA. Padahal dengan adanya informasi yang terdapat pada output tersebut dapat membantu pihak puskesmas untuk mengetahui jumlah kasus ISPA/Pneumonia yang ada di wilayah puskesmas tersebut. Apabila telah mengetahui keadaan kasus pada wilayah tersebut, diharapkan pihak puskesmas dapat menganalisis dan melakukan upaya pencegahan agar jumlah kasus ISPA/ Pneumonia pada wilayah kerja puskesmas tersebut tidak semakin meningkat.

\section{Analisis Sistem Informasi Program Pelaporan ISPA}

Program Pelaporan ISPA yang digunakan tersebut merupakan tipe pengelolaan SIK komputerisasi offline. Pengelolaan ini telah menggunakan komputer namun masih belum terintegrasi secara online ke Dinas Kesehatan Kabupaten/Kota dan Provinsi/Bank Data Nasional. Pengelolaan seperti ini dapat menghambat proses pengambilan keputusan manajemen dan proses pelaporan. Sistem Informasi Kesehatan yang diharapkan adalah yang dapat terintegrasi antar instansi, dengan kata lain menggunakan tipe pengelolaan komputerisasi online (Kemenkes RI, 2016a).

Sistem informasi yang saling berhubungan antara satu sistem informasi dengan yang lainnya sehingga memungkinkan untuk dilakukan pertukaran dan pengiriman data antar sistem disebut dengan Sistem Informasi Kesehatan (SIK) Terintegrasi (Kemenkes RI, 2011). Aliran informasi dari sistem sangat bermanfaat apabila data pada suatu sistem juga diperlukan oleh sistem lainnya, atau output dari suatu sistem dapat dimanfaatkan sebagai input dari sistem lainnya.

Bentuk fisik dari SIK terintegrasi berupa aplikasi sistem informasi yang dihubungkan dengan sistem informasi lain, misalnya aplikasi sistem informasi puksesmas dihubungkan dengan aplikasi sistem informasi rumah sakit, dsb. Adanya SIK terintegrasi memungkinkan untuk pertukaran data antar aplikasi pada setiap instansi (Kemenkes RI, 2011). Dengan adanya SIK terintegrasi, data hanya perlu dimasukkan satu kali dan data tersebut telah tersimpan secara eletronik dan siap diolah maupun dikirim kepada instansi lainnya. SIK terintegrasi akan dapat dimanfaatkan untuk meringankan beban petugas 
dalam hal pencatatan dan pelaporan kesehatan di lapangan.

Selain tipe pengelolaan data, sistem informasi pada form Program Pelaporan ISPA masih kurang pada pemanfaatan output dari tiap menu yang ada. Menu selain input kasus bulanan dan info utama akan menampilkan grafik dari hasil data yang telah diinput pada tiap bulannya. Namun, seringkali grafik tidak memunculkan informasi yang tepat karena input data bulanan kurang lengkap ataupun data pada info utama belum diisi dengan benar. Hal tersebut mengakibatkan pemanfaatan dari output dirasa kurang. Adanya menu output pada form Program Pelaporan ISPA harusnya dapat dijadikan gambaran bagaimana kasus ISPA/ pneumonia pada wilayah kerja tersebut. Selain itu, ada menu yang dapat menjelaskan ketepatan dan kelengkapan data yang dikirim. Namun, tidak dimanfaatkan. Padahal menu tersebut dapat menjadi bahan evaluasi terhadap pelaporan kasus ISPA yang ada di wilayah puskesmas tersebut.

Penelitian yang dilakukan oleh Agusli, Sakuroh dan Nopriyadi (2016) menghasilkan sistem informasi kesehatan berbasis web yang dapat dimanfaatkan oleh petugas puskesmas dengan menggunakan software yang berbentuk halaman situs. Harapannya, dengan penggunaan sistem informasi kesehatan berbasis web, petugas puskesmas dapat lebih akurat dalam mengelola data rekam medis dari pasien. Hal tersebut dapat berguna dalam menjaga akurasi data sehingga menghasilkan informasi yang valid dan berguna.

Sistem informasi kesehatan berbasis web banyak membantu petugas dalam hal akurasi data dan kecepatan proses pengiriman data. Form program pelaporan ISPA yang telah digunakan pada tiap puskesmas di Surabaya juga perlu terintegrasi dengan internet untuk memudahkan proses pengelolaan, pengiriman, serta pengolahan data ISPA dan pneumonia yang membutuhkan proses pelaporan dengan cepat.

\section{Kelebihan dan Kekurangan dari Program Pelaporan ISPA}

Adanya format pengisian pelaporan ISPA yang telah diterbitkan Kemenkes RI memudahkan untuk penginputan data dari masing-masing puskesmas. Apabila format dibuat dengan jumlah baris sesuai dengan jumlah kelurahan yang ada di wilayah puskesmas. Lain halnya dengan Dinas Kesehatan Kota Surabaya khususnya unit Sistem Informasi Kesehatan yang membuat sendiri rekapan data dengan format yang serupa yang dapat mencakup semua kelurahan dan puskesmas di Surabaya.

Format file pelaporan yang masih manual menyebabkan kurang cepatnya pengiriman data dari tiap-tiap puskesmas. Akibatnya, sering terjadi keterlambatan pengiriman data dari puskesmas. Di sisi lain, apabila file tersebut diubah menjadi berbasis web atau online, ditakutkan apabila server sedang down data yang ada dalam sistem akan hilang dan tidak terbackup dengan baik. Maka dari itu, untuk mengantisipasi kehilangan data, pihak SIK masih memakai sistem pelaporan dengan format manual dan dikirim ke pihak SIK satu per satu sesuai dengan pemegang program dari tiap puskesmas.

File excel program pelaporan ISPA memuat beberapa menu output yang dapat dimanfaatkan sebagai hasil gambaran dari banyaknya kasus pneumonia dan ISPA yang terjadi di wilayah kerja puskesmas tertentu. Namun, output tersebut kurang dimanfaatkan sehingga monitoring kasus kurang diterapkan.

\section{SIMPULAN DAN SARAN}

\section{Simpulan}

Program Pelaporan ISPA merupakan format file excel yang dibuat oleh Kementerian Kesehatan Republik Indonesia untuk mengumpulkan dan merekap data terkait ISPA dan pneumonia. File tersebut merupakan file dengan tipe pengelolaan komputerisasi offline yang diisi secara offline berdasarkan data yang ada di puskesmas. File tersebut memuat beberapa menu yang dapat dimanfaatkan untuk proses pengolahan dan analisis data terkait ISPA dan pneumonia.

Format file yang masih manual dan belum terintegrasi dengan internet (online) membuat pengiriman laporan menjadi lebih lama. Akibatnya ketepatan dari pengiriman laporan dinilai kurang. Selain itu, pihak puskesmas harus bolak balik mengirimkan file apabila terdapat 
kesalahan. Padahal apabila menerapkan SIK secara online yang terintegrasi, data hanya dimasukkan satu kali dan akan tersimpan secara elektronik untuk kemudian dimanfaatkan ataupun diolah

File excel program pelaporan ISPA memuat beberapa menu output yang dapat dimanfaatkan sebagai hasil gambaran dari banyaknya kasus pneumonia dan ISPA yang terjadi di wilayah kerja puskesmas tertentu. Namun, output tersebut kurang dimanfaatkan sehingga monitoring kasus kurang diterapkan. Padahal apabila output tersebut dimanfaatkan tidak menutup kemungkinan akan mengurangi jumlah kasus ISPA/pneumonia yang terjadi di Kota Surabaya.

\section{Saran}

Adapun rekomendasi yang dapat diberikan terkait pemanfaatan sistem informasi Program Pelaporan ISPA adalah perlunya pengembangan sistem informasi Program Pelaporan ISPA dengan tipe pengelolaan data komputerisasi online agar bisa membantu pengumpulan laporan dengan lebih cepat dan efisien. Hal tersebut dapat mendukung upaya pengurangan jumlah kasus ISPA/pneumonia yang terjadi di Kota Surabaya. Selain itu, kegiatan sosialisasi terkait pengisian form Program Pelaporan ISPA kepada petugas puskesmas juga perlu dilakukan agar petugas lebih teliti, tepat dan lengkap dalam pengisian form laporan tersebut.

\section{DAFTAR PUSTAKA}

Agusli, R., Sakuroh, L., Nopriyadi, 2016. Perancangan Sistem Informasi Kesehatan (Puskesmas Keliling) Berbasis Web. Jurnal Sisfotek Global, 6(2), pp.47-53.

Aulia, I., Chamid, M.S., Andari, S., 2017. Pemodelan Pneumonia pada Balita di Surabaya Menggunakan Spatial Autoregressive Models. Jurnal Sains dan Seni ITS, 6(1), pp.23373520 .
Depkes RI, 2003. Panduan Praktis Surveilans Epidemiologi Penyakit. Jakarta: Departemen Kesehatan Republik Indonesia.

Dinkes Kota Surabaya, 2015. Laporan Tahunan Tahun 2015. Surabaya: Dinas Kesehatan Kota Surabaya.

Herlambang, T.W., Aknuranda, I, Saputra, M.C., 2018. Pengembangan Sistem Informasi Kesehatan Berbasis Web Berdasarkan Model Organisasi dan Manajemen Kesehatan Primer "ANDAL". Jurnal Pengembangan Teknologi Informasi dan Ilmu Komputer, 2(4), pp.16021610.

Irianto, K., 2014. Epidemiologi Penyakit Menular dan Penyakit Tidak Menular. Bandung: Alfabeta.

Ismanto, A., 2010. Pemanfaatan Teknologi Informasi Berpengaruh terhadap Kinerja Individu Mahasiswa Jurusan Akuntansi Perbanas Surabaya. Skripsi. Sekolah Tinggi Ilmu Ekonomi Perbanas Surabaya.

Kemenkes RI, 2011. Petunjuk Teknis Sistem Informasi Kesehatan. Jakarta: Kementerian Kesehatan Republik Indonesia.

Kemenkes RI, 2012. Jurnal Pengendalian Penyakit dan Penyehatan Lingkungan. Jakarta: Kementerian Kesehatan Republik Indonesia.

Kemenkes RI, 2013. Riset Kesehatan Dasar. Jakarta: Badan Penelitian dan Pengembangan Kesehatan Kementerian Kesehatan Republik Indonesia.

Kemenkes RI, 2016a. Buletin Jendela Data dan Informasi Kesehatan: Tantangan e-Kesehatan di Indonesia. Jakarta: Kementerian Kesehatan Republik Indonesia.

Kemenkes RI, 2016b. Profil Kesehatan Indonesia 2015. Jakarta: Kementerian Kesehatan Republik Indonesia.

Last, J., 2001. A Dictionary of Epidemiology. New York: Oxford University Press. 